New ICMI Study Series

Maria G. Bartolini Bussi

Xu Hua Sun Editors

Building the

Foundation: Whole

Numbers in the

Primary Grades

The 23rd ICMI Study 


\title{
Chapter 11 \\ How to Teach and Assess Whole Number Arithmetic: Some International Perspectives
}

\author{
Jarmila Novotná (D, Berinderjeet Kaur (i) \\ Ann Gervasoni (D), Mike Askew (D), Michiel Veldhuis (D), Catherine Pearn (D), \\ and Xu Hua Sun
}

\subsection{Introduction}

\subsubsection{About the Chapter}

In accordance with the programme components at the ICMI Study 23 Conference in Macao (Theme 4), this chapter focuses on the diverse theoretical and methodological frameworks that capture the complex relationship between whole number learning, teaching and assessment. Its aim is to bring these diverse perspectives into conversation.

The importance of the theme for students' development of understanding mathematics, and their overall learning, is obvious. This is highlighted in the Discussion

Electronic Supplementary Material The online version of this chapter (doi:10.1007/978-3-31963555-2_11) contains supplementary material.

The first two authors wrote the chapter with the collaboration of other working group members.

The first author was supported by the project PRVOUK P15 The school and teaching profession in the context of growing educational demands.

The last author was supported by Research Committee, University of Macau, Macao, China (MYRG2015-00203-FED). The opinions expressed are those of the author.

J. Novotná $(\bowtie)$

Charles University, Prague, Czech Republic, and Laboratoire "Culture et Diffusion des

Savoirs", Université de Bordeaux, Bordeaux, France

e-mail: jarmila.novotna@pedf.cuni.cz

B. Kaur $(\bowtie)$

National Institute of Education, Nanyang Technological University, Singapore, Singapore e-mail: berinderjeet.kaur@nie.edu.sg

A. Gervasoni

Monash University, Melbourne, Victoria, Australia

(C) The Author(s) 2018

M.G. Bartolini Bussi, X.H. Sun (eds.), Building the Foundation: Whole

Numbers in the Primary Grades, New ICMI Study Series,

https://doi.org/10.1007/978-3-319-63555-2_11 
Document (this volume, Appendix 2) as well as in other chapters of the book. There are many approaches to WNA teaching and assessment throughout the world and within countries. Describing all approaches cannot be presented in one chapter of the book. Instead, the authors present one concrete example of school practice - the lesson observed by ICMI23 participants at a primary school in Macao - and use the lesson as a stimulus for discussing ideas about teaching, learning and assessing WNA.

The chapter is divided into seven sections (including this introductory text with the overview of the Theme 4 programme). The focus for all sections is how teachers promote the development of students' metacognitive strategies during their learning of WNA. Each section develops an important aspect of the theme. A description of the Macao Primary School lesson is first presented (Sect. 11.2). This provides the context for the subsequent sections, except for the one focusing on textbooks (as during the lesson textbooks were not explicitly used). The two versions of the variation theory (Sect. 11.4) and the theory of didactical situations (Sect. 11.5) are used as lenses to interpret the lesson. How teachers' knowledge is related to their teaching approaches is discussed in Sect. 11.3, while Sects. 11.6 and 11.7 focus, respectively, on assessment and textbooks which are significant domains for the teaching and learning of WNA.

The topics discussed in this chapter each have important implications for teacher education. These are discussed in Chap. 16. Furthermore, there were several questions from the Discussion Document (this volume, Appendix 2) discussed during the working group 4 sessions and published in the conference proceedings. In order to show the richness of discussions among the working group 4 participants, the descriptions of all contributions to the topic are summarised in Sect. 11.1.2. Readers interested in more detailed information about any discussed aspect can find the corresponding papers in the ICMI Study 23 Proceedings.

\subsubsection{What Was Presented at the Conference: Overview}

Theme 4 addressed general and specific approaches to teaching and assessing WNA. In the thematic group, theoretical and methodological frameworks that could capture the complex relationship between whole number learning, teaching and

\footnotetext{
M. Askew

University of the Witwatersrand, Johannesburg, South Africa, and Monash University, Melbourne, Victoria, Australia

M. Veldhuis

Utrecht University, Utrecht, The Netherlands

C. Pearn

The University of Melbourne, Melbourne, Victoria, Australia

X.H. Sun

Faculty of Education, University of Macau, Macao, China
} 
assessment were considered. The background question for all contributions to Theme 4 was the same as for this chapter: how can teachers promote the development of students' metacognitive strategies during the learning of WNA?

Fourteen papers written by authors from 13 countries were accepted for this theme. They addressed the issues of teaching and assessing WNA from different perspectives. The contributions by participants from many countries offered a unique opportunity to compare and contrast different approaches to teaching and assessing WNA.

For presentation and discussion, the papers accepted for Theme 4 were divided into five subgroups according to their main focus. The summary that follows uses these subgroups as an organisational structure. We are aware that it is not possible to make disjoint groups of papers when attending to their main focus. Note: there is no ranking in the order of topics.

\subsubsection{Teaching Approaches}

Askew (2015) focused on place value in Grade 2 in South Africa. He argued that within a context focused around whole-class teaching, it is still possible to engage learners with mathematics in ways that go beyond merely reproducing procedures demonstrated by the teacher.

Cao et al. (2015) presented the characteristics of the Chinese traditional approach from the perspectives of content, organisation, the arrangement of teaching, ways of presenting and cognitive demand level with a special emphasis given to multiplication tables.

\subsubsection{Knowledge of Teachers}

Ekdahl and Runesson (2015) examined shifts in the nature of responses of three South African Grade 3 teachers to students' incorrect answers when teaching the part-whole relationship in additive missing number problems and discuss consequences.

Lin (2015) focused on teaching the structure of standard algorithms for multiplication with multi-digit multipliers via conjecturing as one of effective instructional approaches to teaching multiplication with multi-digit multipliers.

Barry et al. (2015) investigated the variables that determine the difficulty of an additive problem. They showed that the knowledge of variables that determine it differs considerably from one teacher to another. They justified that the roots of these differences are in the differences of teachers' pedagogical beliefs.

\subsubsection{Curriculum}

This group of contributions is not fully homogeneous. It includes papers focusing on WNA curricula in different countries, on the outcomes when applying curricula and on the influence of using different types of textbooks. 
Kaur (2015) presented the primary school mathematics curriculum in Singapore, focusing on the model method, a tool for representing and visualising relationships. In Singapore, it is a key heuristic that students use for solving WNA word problems.

Wong et al. (2015) reported on Macao's 15 years of experiences of primary mathematics education, after the official handover of the former Portuguese enclave to China in 1999. They argued that no educational system can provide Macao with a ready-made curriculum model.

Sensevy et al. (2015) analysed the principles and rationale of a curriculum for WNA teaching in the first grade in France.

Brombacher (2015) reported on the situation in Jordan. He suggested that deliberate and structured daily focus on foundational whole number skills can support the development of children's ability to do mathematics with understanding.

\subsubsection{Textbooks}

Alafaleq et al. (2015) examined how equality and inequality of whole numbers are introduced in primary mathematics textbooks in China, Indonesia and Saudi Arabia.

Zhang et al. (2015) investigated four sets of primary mathematics textbooks used in Hong Kong using content analysis.

\subsubsection{Assessment and Evaluation of WNA}

Zhao et al. (2015) discussed challenges that Chinese primary teachers faced when supposed to implement classroom assessment techniques.

Gervasoni and Parish (2015) presented the results of one-to-one assessment with nearly 2000 Australian primary school students. They highlighted the challenge of meeting each student's learning needs, and demonstrated the complexity of classroom teaching.

Pearn (2015) compared the reactions of the Grade 4 teachers in one school (with the same curriculum) with their students' results on a WNA test.

\subsubsection{The Discussion in the Working Group}

The eight 1-hour sessions in the working group were organised in two different forms. The first five sessions were devoted to the discussion of the participants' accepted papers. The papers were grouped according to their topics dealt with: teaching approaches, knowledge of teachers, curriculum, curriculum and textbooks and assessment of WNA. Then three discussion sessions followed. Their themes of discussion were: teachers' knowledge of their students' understanding, performance and personality traits that can help teachers plan for effective teaching strategies; 
multicultural approaches and traditions of teaching WNA; the role of textbooks and artefacts in teaching WNA; and the role of custom-made curriculum to improve the learning of WNA. The work was organised partly in the mixture of small group and plenary discussions.

The programme was enriched by the contribution of Marianela Zumbado Castro from Costa Rica (CNAP). Her presentation covered the information about the important development of number meaning in the Costa Rican mathematical programme. She highlighted approaches to calculations and approximations and the use of multiple representations in troubleshooting. These domains were covered from an eminently pragmatic perspective that emphasised student action. She emphasised that numbers occupy a big place from first to sixth graders, in order to promote mathematical processes and positive attitudes for its proximity to the context and its close connection with the other areas.

It is obvious that the topics dealt within WG4 were not disjoint with other WGs. There were overlaps with other working group topics as well as with the panel about teacher education. However, the common topics were tackled from different perspectives in each part of the programme and can be seen as complementing each other.

\subsection{A Mathematics Lesson Focused on Addition Calculations with Two-Digit Numbers at a Primary School in Macao}

\subsubsection{Introduction}

Teachers in Macao in common with primary school teachers across the world are working to transform their approach to teaching mathematics. They have a strong focus on students learning mathematics with deep conceptual understanding and developing creative thinking. In this chapter, we aim to explore issues in the teaching of arithmetic with reference to an illustrative lesson that we observed at a primary school in Macao in June 2015. The Grade 1 class we observed were all enthusiastic and well focused on the activities and learning throughout the lesson. This school, we were told, aims to ensure that the students will be well behaved, enjoy their lives and be good at creative thinking for the future. The mathematics team of 14 teachers was described by the principal as progressive and innovative. They meet together in different levels at least once per week to share their objectives and activities. They also engage in research practices focused on school-based studies of teaching aimed to promote positive changes in teaching and learning. Every teacher is responsible for teaching one demonstration lesson and observing 20 lessons in an academic year so that the mathematics teachers can learn from each other. The school also organises training for elite mathematics teams from the kindergarten to the grade 9 who join mathematics competitions. This activity aims to enhance logical thinking and project-based practice. 


\subsubsection{The Lesson}

The Grade 1 students we observed have five mathematics lessons per week and one mathematics reading lesson per week (a mathematics reading lesson involves stories and written problem-solving, mathematical games, project-based activities and hands-on activities). The lesson began with a lead in stage during which students engaged in 3 min of mental calculation practice. The lesson proceeded with several stages during which the students explored a range of situations and strategies for adding two-digit numbers. Throughout the lesson, the teacher circulated to observe and discuss the students' strategies and to select students to describe and explain their calculation strategy to the whole class. In one stage of the lesson, the students worked in fours to use models to represent the calculation and solution. A variety of real-world calculations and bare number calculations were investigated and solved and discussed. The Grade 1 students we observed were all enthusiastic and well focused on the activities and learning throughout the lesson (Electronic Supplementary Material: Sun 2017b).

The setting and sequence of activities of the lesson are summarised in Table 11.1 shown below.

Table 11.1 Setting and sequence of activities of the lesson

\begin{tabular}{|c|c|}
\hline Seating organisation for the lesson & \multirow[t]{2}{*}{ See Fig. 11.1} \\
\hline The class of 22 Grade 1 children (6-year-olds) sat in pairs at their desks. & \\
\hline Introduction and welcome & \multirow[t]{2}{*}{ See Fig. 11.2} \\
\hline $\begin{array}{l}\text { The lesson began with a warm greeting from the teacher and a respectful bow } \\
\text { from the students. }\end{array}$ & \\
\hline Stage 1 lead in: fluency with number facts & \multirow[t]{3}{*}{ See Fig. 11.3} \\
\hline $\begin{array}{l}\text { The first activity in the lesson (the lead in stage) focused on the students } \\
\text { practising number facts - number combinations for ten. The students were } \\
\text { shown a set of number facts to solve and recorded their answers. This practice } \\
\text { was timed with students recording when they completed all the calculations. } \\
\text { The teacher roved around and observed the students as they worked. }\end{array}$ & \\
\hline $\begin{array}{l}\text { The answers were corrected as a group with the stated aim being for the } \\
\text { students to improve their previous score and time. The teacher enthusiastically } \\
\text { encouraged the students to improve and asked them to state if they had } \\
\text { improved their time and score. }\end{array}$ & \\
\hline $\begin{array}{l}\text { Stage } 2 \text { situation setting: addition of a two-digit number and a one-digit } \\
\text { number without regrouping - using pictorial representations of realistic } \\
\text { contexts }\end{array}$ & \multirow[t]{2}{*}{ See Fig. 11.4} \\
\hline $\begin{array}{l}\text { In this section of the lesson (situation setting), the teacher presented a realistic } \\
\text { situation for the students to explore. The first problem showed a pictorial } \\
\text { representation of four packets of ten candies and three single candies. They } \\
\text { needed to work out the total: } 40+3=43 \text {. }\end{array}$ & \\
\hline
\end{tabular}


Table 11.1 (continued)

The next situation presented was a pictorial representation of candies organised onto trays of ten and loose candies. The calculation was $25+2=27$. Once the problem was solved the teacher guided a discussion about the calculation strategies used. The photo shows splitting the 25 into tens and ones and then grouping the ones to calculate the total easily.

Finally, the students considered a situation involving pencils organised into boxes of ten and some loose pencils. The calculation involved two-digit numbers. The solution discussed by the teacher and students considered grouping the boxes of ten together and adding the number of loose pencils.

$25+20=45$

$20+20+5=45$

Stage 3 group counting and sharing: addition with two-digit numbers and one-digit number (with regrouping ones)

This stage of the lesson was described as the group counting and sharing stage during which the students were expected to communicate, conceptualise and inquire. The context was 'party time'; materials (candies) were used to represent the situation and the calculation strategies for $24+9=33$. The students worked in groups of four to discuss the possible strategies for this calculation, while the teacher moved between the groups to observe, listen in and discuss the strategies. Students were selected to come to the front of the class and explain their strategies using the document camera and interactive white board. The teacher explored three different strategies with the class. She had anticipated these strategies before the lesson and prepared the posters for display.

$23+(1+9)=33$

$20+(4+9)=33$

$(24+6)+3=30+3$

Stage 4 Practice Stage: calculation competition

This stage of the lesson had three components. During Practice Stage 1, the student found solutions to a set of problems while the teacher circulated to observe and discuss the strategies. The teacher again selected several students to come to the front to explain their calculation strategies. The teacher highlighted carefully the different strategies used. However, after only completing one of the four calculations on the board, the teacher moved to Stage 2. In Practice Stage 2 the students worked in pairs and were asked to choose their favourite digits from an envelope to make a new two-digit number. The teacher gave them another card with the addition sign and a single digit number ( 9 followed by 7 ). The students had to add the one-digit number to their two-digit number. Several strategies were shared with the class.

One child explained a calculation that bridged 100: $95+9=104$. She had some difficulty describing her strategy to the class and the teacher assisted her.

Practice Stage 3 was a return to the calculating competition (Practice Stage 1) where the students were encouraged to share their answers and their strategies.

Lesson summary

The conclusion of the lesson was a summary by the teacher about what they had explored and learnt during the lesson. The teacher emphasised that the students could use the 'making 10' strategy to add a two-digit number and a one-digit number. 


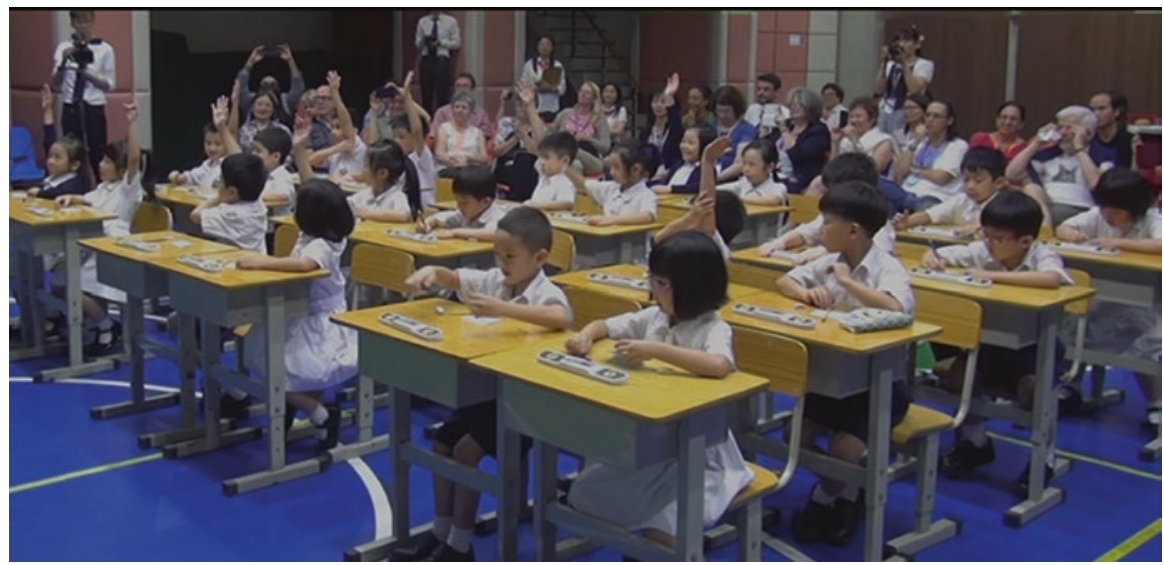

Fig. 11.1 Seating organisation

Fig. 11.2 Introduction and welcome

Fig. 11.3 Lead in: fluency with number facts
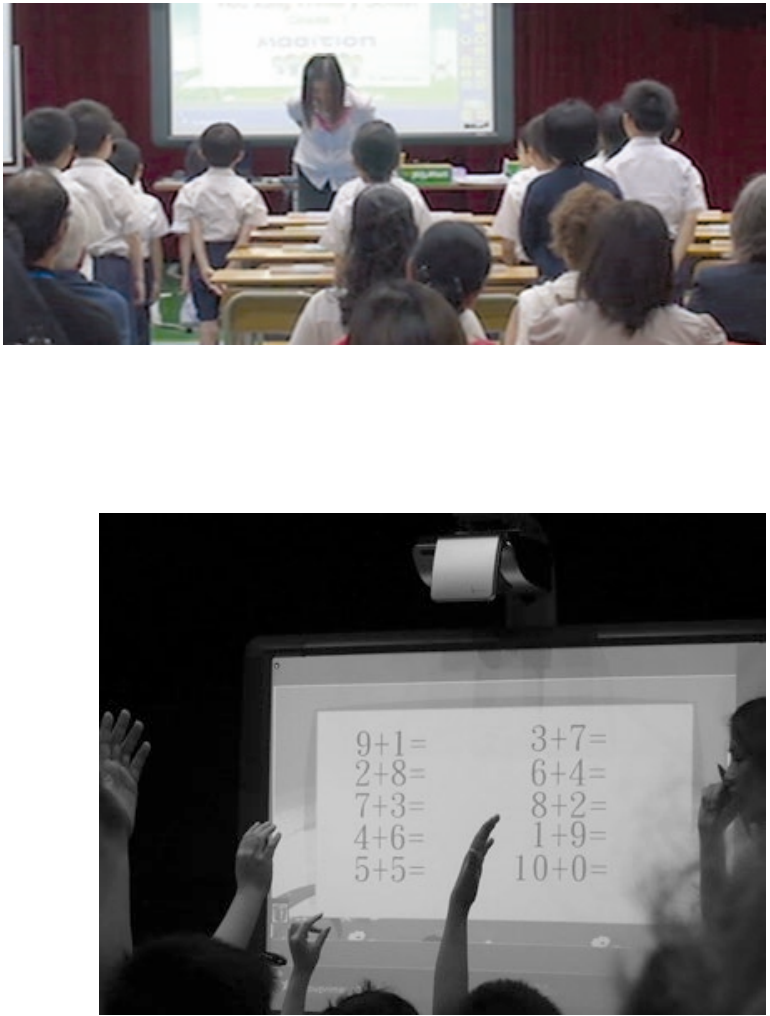
Fig. 11.4 First situation setting

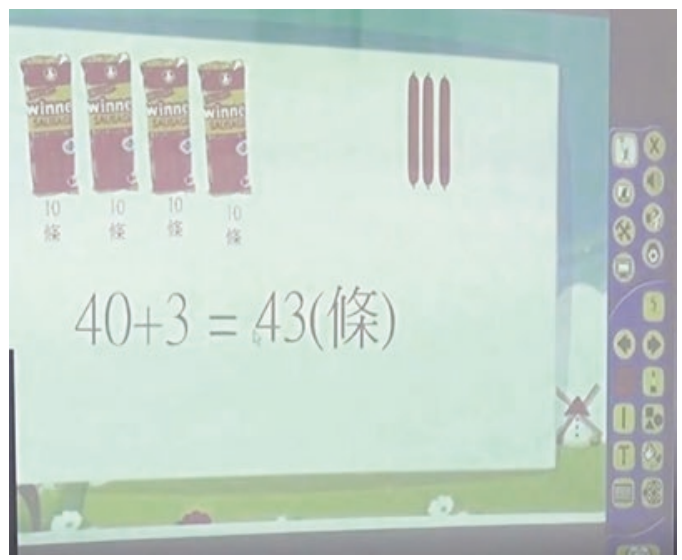

Fig. 11.5 Second situation setting

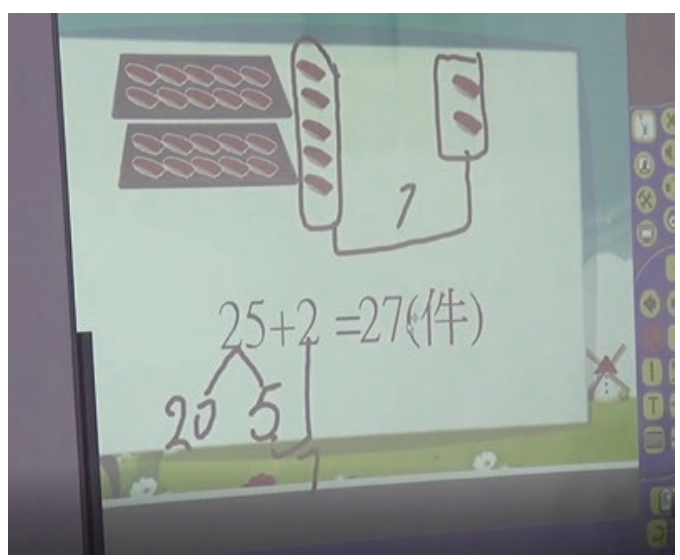

Fig. 11.6 Third situation setting

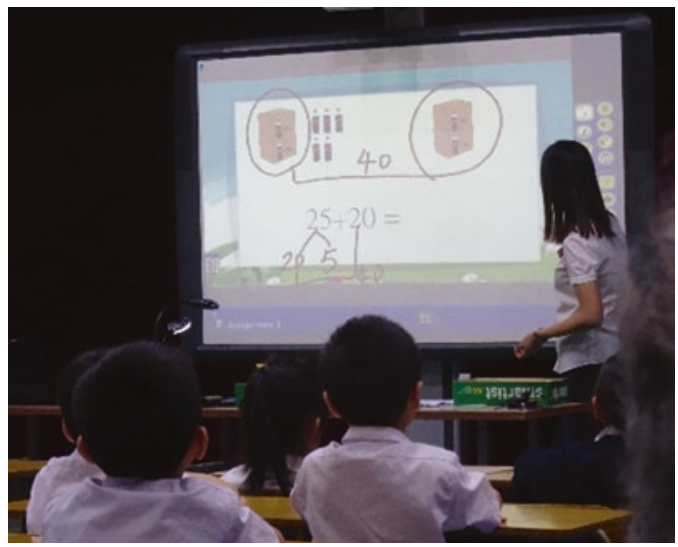


Fig. 11.7 Group counting and sharing

Fig. 11.8 Practice stage 1

Fig. 11.9 Practice stage 2
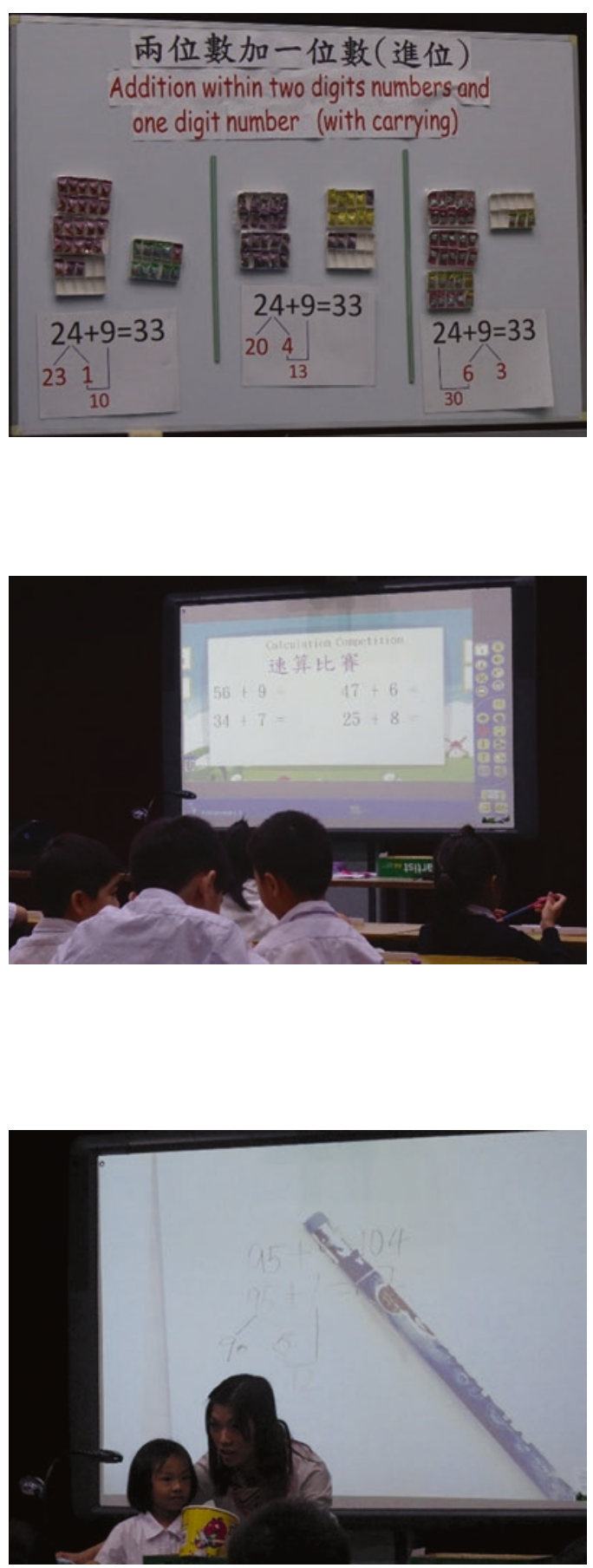
Fig. 11.10 Practice stage 3

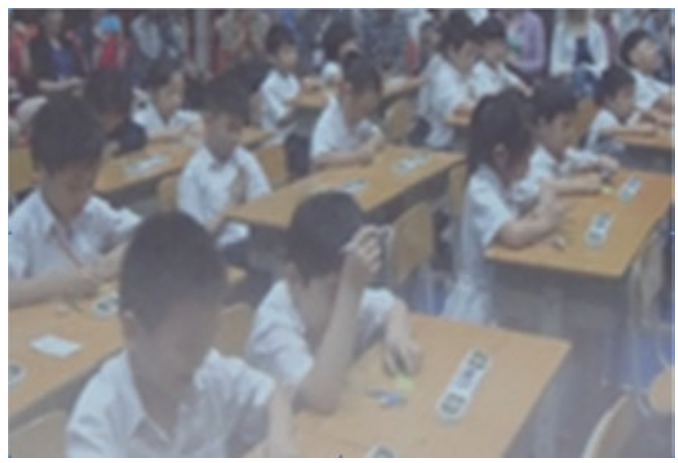

\subsection{The Impact of Teachers' Knowledge of Pedagogy, Learning Trajectories, Mathematics and Students (Cognitive, Social, Emotional, Context, etc.) on Children's Learning of Whole Number Arithmetic}

\subsubsection{Introduction}

Many everyday calculations involve adding combinations of one-digit and two-digit numbers. This is so whether we are shopping, measuring for sewing or a building project or analysing data in a rainfall graph. This partly explains why adding oneand two-digit numbers is a key focus in primary school mathematics education. However, approaches to teaching this type of calculation vary within and between countries. The teaching approach in many countries today emphasises children learning a variety of arithmetic strategies so that they can successfully and efficiently perform calculations mentally. However, other approaches draw upon textbooks that focus on children learning standard written methods for performing these calculations. It is important for teachers to understand the affordances and limitations of various teaching approaches for children's arithmetic learning.

\subsubsection{Responding to Children's Current Knowledge of Whole Number Addition and Subtraction}

The Macao lesson vignette described earlier in this chapter provides an example of an approach to teaching children to perform calculations with one-digit and twodigit numbers that would be recognised in many countries (e.g. Singapore, Germany, Australia, Canada, Thailand). The teacher used her knowledge (assessment) of the students' current mathematics knowledge and pedagogy to select tasks with an appropriate level of challenge and that aligned with the curriculum expectations. 
She made a concerted effort to motivate the students to engage in the lesson activities and work hard to improve their knowledge, and she was encouraging of the students' efforts to learn. The teacher provided the children with time to work on their own, time to work in small groups to discuss ideas and solutions and time to observe and listen to the solutions presented by several students. This suggests that she may be influenced by social-cultural perspectives (e.g. Vygotsky 1980) in designing the lesson structure. However, this may be the teaching norm in her school community. With respect to the tasks, the teacher provided a balance between tasks that involved bare number calculations and those that were connected to everyday situations. There was also the opportunity in the lesson for children to use materials and pictures to model their solutions processes to support their mathematical reasoning. There was an overarching focus on the children understanding the solution strategies they were using or viewing. However, in contrast to the approach in Singapore (Kaur 2015) and advocated by Bruner (1960), there was little use of materials being used to assist individual children's learning progress from arithmetic reasoning based on concrete representations through to pictorial and abstract representations. In contrast, the approach in the Macao lesson required all the children to engage with concrete, pictorial and abstract models at set points in the lesson. There was no sense that the teacher was using formative assessment to select concrete, pictorial or abstract models for individual children based on their current understanding or to encourage the children to select these different representations themselves.

One set of tasks in this lesson involved the students performing calculations with numbers such as $25+9$. Pictures of snacks in boxes of ten and loose ones were used to represent the quantities and to model the various solution processes that were predetermined by the teacher. This set of solutions was elicited from the children and discussed as a class group to build understanding and provide children with examples of strategies they may not have spontaneously considered. This enabled the class to discuss the advantages of various strategies in relation to the numbers involved. This teaching approach of inviting children to demonstrate and discuss various solutions is widely used in countries such as Japan (Murata and Fuson 2006), the Netherlands (RME; van den Heuvel-Panhuizen and Drijvers 2014), Germany (Selter 1998) and Australia (Clarke et al. 2002).

One advantage of all the children in a class performing the same calculations is that they can all participate in a meaningful discussion about the various arithmetic strategies used. However, tasks such as $25+9$ do little to develop creativity, challenge or persistence. An alternative approach is to use an open task that enables children to create and discuss a range of solutions. For example, the students may be asked to create a set of solutions for the task, 'Ivy added two numbers and the sum was more than 32 . What might the numbers be?' This open task encourages the students to persist in producing a range of solutions that are creative and complex enough to challenge them to think hard. The solutions and arithmetic strategies can then be discussed as a class to extend the understanding of all. This approach is advocated by Sullivan et al. (2015). 
The challenge for a teacher during a lesson such as the one described earlier is to plan how the learning may be differentiated and how the lesson can develop creativity, which was a stated aim of Hou Kong Primary School in Macao and is highlighted as an important goal of mathematics education in many international settings. In the observed lesson, it seemed that all students were able to successfully perform the calculations, but some were clearly more confident than others, and some children may have been able to solve more complex problems, given the opportunity. However, the tasks and teaching actions were not adapted to respond to any formative assessment data collected by the teacher during her observations or discussion with children. This issue of task differentiation and developing creative mathematical thinking are important considerations when considering highly effective teaching of whole number arithmetic. Further, in many countries, where class sizes are very large, the differences in the knowledge of the students may pose the teacher with challenges. Thus differentiating tasks and instruction is an important role for the teacher when children are learning whole number arithmetic.

\subsubsection{Differentiating Instruction Based on Children's Current Knowledge}

Children's development of heuristic strategies for addition and subtraction has been well described (e.g. Steffe et al. 1988; Murata and Fuson 1997). Such research formed the basis for describing the six addition and subtraction strategies growth points established during the Early Numeracy Research Project (Clarke et al. 2002) to describe children's learning in this domain. Growth points are established for a child following assessment by the teacher using a detailed scripted one-on-one assessment interview (Clarke et al. 2002). This is a common assessment approach in Australia and New Zealand (Bobis et al. 2005). A feature of assessment interviews is that they enable the teacher to observe children as they solve problems to determine the strategies they used and any misconceptions (Gervasoni and Sullivan 2007). They also enable teachers to probe children's mathematical understanding through thoughtful questioning (Wright et al. 2000) and observational listening (Mitchell and Horne 2011).

Growth point results for nearly 2000 Grade 1 to Grade 4 students (Fig. 11.11) collected during the Bridging the Numeracy Gap Project (Gervasoni et al. 2011) confirm that there is a wide distribution of children's addition and subtraction strategies growth points in each class. These data indicate that $96 \%$ of Australian Grade 1 children, $75 \%$ of Grade 2 children, $46 \%$ of Grade 3 children and $30 \%$ of Grade 4 children used counting-based strategies for calculations, such as $4+4$ and $10-3$. The fact that so many Grade 4 children remain reliant on counting strategies and concrete models for calculating and that almost no Grade 4 students could solve mental calculations involving two-digit and three-digit numbers (growth point 6) is at odds with the tasks typically found in Grade 4 textbooks that involve calculations 


\section{Addition and Subtraction Strategies Growth Points Distributions Gr 1-Gr 4}

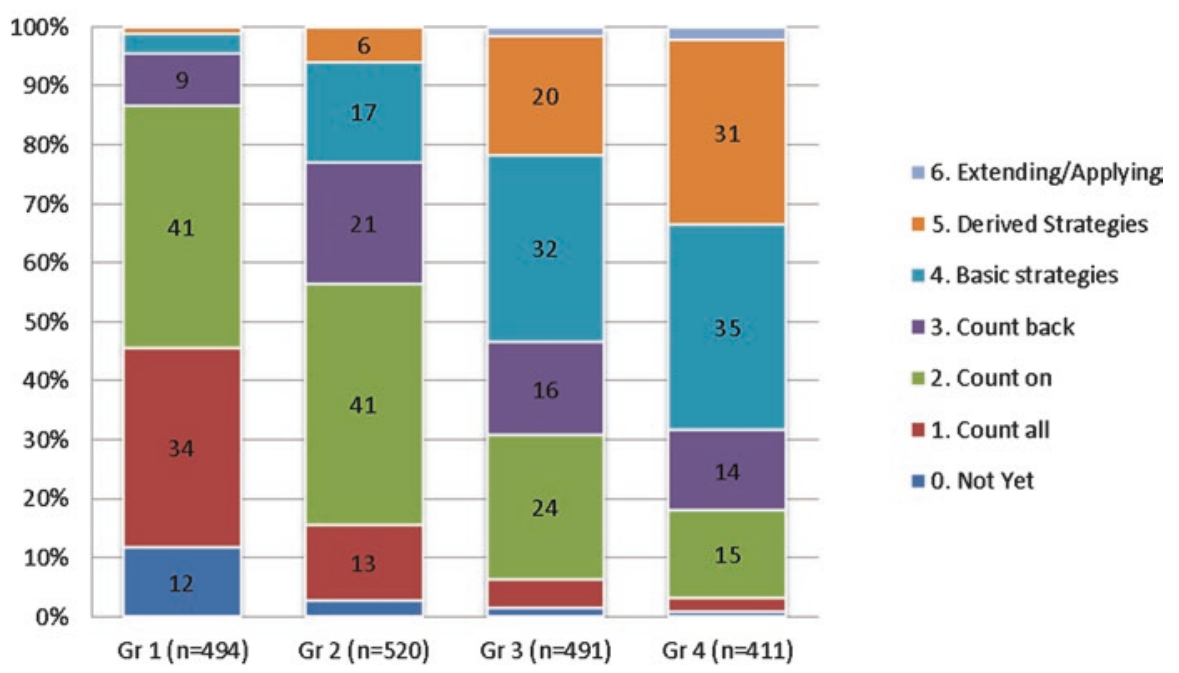

Fig. 11.11 Addition and subtraction growth point distribution for Grade 1-4 children

with much larger numbers. Data such as these demonstrate the need for teachers to understand the current knowledge of students through observation of their calculation strategies, understand the typical developmental pathway in this domain and understand the teaching strategies that respond to the individual needs of students so that they can differentiate tasks. This is not possible if teachers only use written tests (Clements and Ellerton 1995) or one textbook for a class that does not differentiate learning and extend understanding. Rather, if teachers observe that a child uses a count-all strategy (growth point 1) and refer this to a learning framework, then they can appreciate that a child's shift to using a count-on strategy (growth point 2) or abstract reasoning strategies (growth point 4) requires the teacher to hide some of the physical models to prompt children to produce a mental image that enables them to count-on or reason abstractly.

In summary, there is no single 'formula' for describing children's whole number knowledge or the instructional needs of children in a particular grade. Meeting the diverse learning needs of children requires teachers to be knowledgeable about how to identify each child's current mathematical knowledge and how to customise their teaching accordingly. This calls for rich initial and formative assessment tools capable of revealing the extent of children's whole number knowledge and calculation strategies and an associated framework of growth points capable of guiding teachers' curriculum and instructional decision-making. Assisting children to learn mathematics is complex, but teachers who are equipped with the pedagogical knowledge and actions necessary for responding to the diverse needs of individuals are able to 
provide children with the opportunities and experiences that will enable them to thrive mathematically.

\subsection{View of Lesson through the Lens of Variation Theory}

Variation theory has come to the foreground in the last decade in different parts of the world (Huang et al. 2006) as a lens through which the classroom learning can be designed, described and analysed. First we look at the 'indigenous' approach to variation problems (Sun 2011a, b, 2016), in order to give an insider's perspective on the lesson (design and functioning), and second we situate the lesson within the international debate (e.g. Marton et al. 2004) about the observed lesson.

\subsubsection{The Insider's Perspective: 'Indigenous'Variation Practice}

In this section, we examine the lesson through a lens of 'indigenous' variation practice as a means of providing the insider perspective, in order to enhance comprehensive understanding of the lesson. In this section, we mainly focus on the situation of the candy box problem. In order to understand the classroom process, it is necessary first to describe the past experience of the students, which followed the Chinese curriculum as it is described in Chinese textbooks. The importance of textbooks in Chinese curriculum must be emphasised, as teachers follow the textbooks' directions (which draw on the standards) very carefully. As said in the previous sections, this lesson took place close to the end of the school year; hence, students were already familiar with the previous content.

\subsubsection{The Prior Students' Knowledge}

The students' previous knowledge about different cases of addition and subtraction had been developed, fostering grouping, regrouping and ungrouping, following the Chinese tradition. Consider the following examples of activities taken from their textbook for the first months of the first grade (Fig. 11.12).

The image on the left provides a good example of explicit variation. In the first line, there is the standard notation for decomposing 10 in different ways. Then, in each of the following lines, there is a scheme (the problem situation, given in iconic form) referring to one of the above decomposition. Each problem is interpreted in different ways, according to the indigenous variation practice (OPMC, i.e. one problem, multiple changes, Sun 2011b), hinting at addition and subtraction together. The same problem is focused at the same time with different interpretations, creating a 

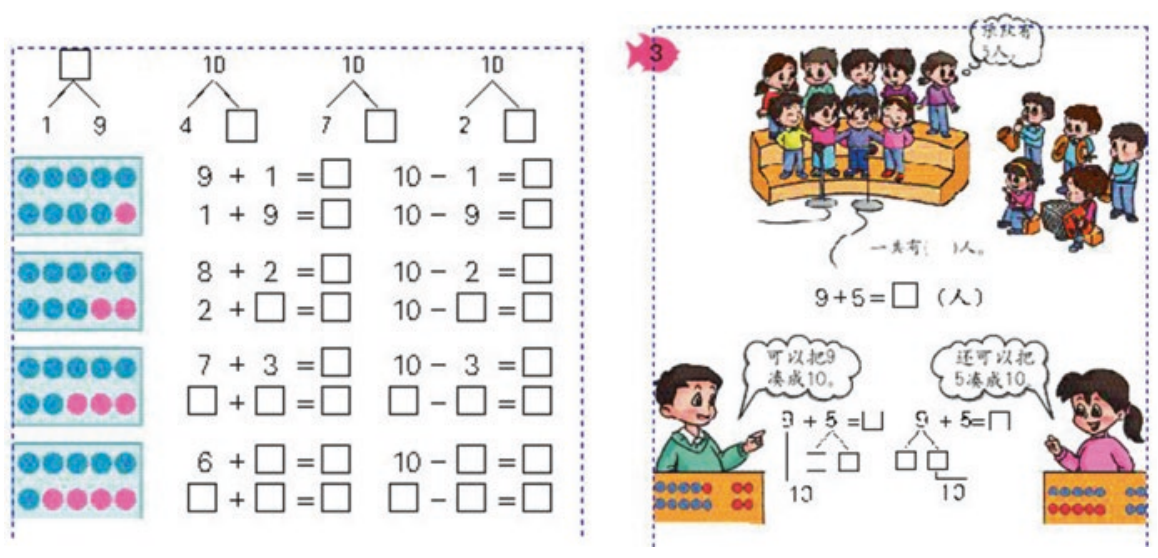

Fig. 11.12 Examples introducing the decomposition of 10 in the Chinese textbook (Mathematics Textbook Developer Group for Elementary School, 2005, vol. 1)

very strict link between addition and subtraction and a focus on algebraic thinking (relations between numbers). In the same image, another explicit variation appears increasing the quantity of missing numbers to be detected and changing their position in the mathematical expressions. This is expected to be done in the same lesson as one textbook page is used in one lesson. This approach is very different from other ones practised in some Western countries, where addition and subtraction may be taught separately (see Sun et al. 2013 for Portugal; Bartolini Bussi et al. 2013 for Italy).

The image on the right exploits the standard notation for decomposing 10 in order to solve, in different ways, the addition $9+5$ with regrouping (OPMS, i.e. one problem, multiple solutions, Sun 2011b).

Besides that, students know already how to add tens and how to add two-digit numbers without regrouping. Hence, the students knew what was necessary to handle the situation of the day, concerning the candy boxes and the addition with regrouping $24+9$.

\subsubsection{The Lesson Plan: The Situation of the Day}

According to the framework of Chinese open classes (Chap. 16), the lesson plan was given to the international observers a few days in advance. It contained details about the organisation, the teaching topic (addition within two-digit numbers and one-digit number with regrouping), the learning objectives and the students' previous knowledge (Bartolini Bussi and Sun 2015).

The situation of the day was the problem of the candy boxes: it was carefully described in the lesson plan (excerpt) (Table 11.2). 
Table 11.2 The lesson plan (excerpt)

\begin{tabular}{|c|c|c|}
\hline Situation setting & $\begin{array}{l}\text { (a) Teacher gives a situation to the class. 'There are many } \\
\text { guests in our school today. So, Miss Amanda prepares } \\
\text { some food for them. Class, can you help me count the } \\
\text { food as fast as you can?' }\end{array}$ & $15 \mathrm{~min}$ \\
\hline \multirow[t]{2}{*}{ Problem solving } & (a) Students work in groups. & \\
\hline & (b) Provide some candies to each group and let them count. & \\
\hline \multirow{10}{*}{$\begin{array}{l}\text { Group counting and } \\
\text { sharing } \\
\text { (communication, } \\
\text { conceptualising, } \\
\text { inquiring) }\end{array}$} & $\begin{array}{l}\text { (a) T invites some group to report their finding about how } \\
\text { to count the candies altogether. }\end{array}$ & \\
\hline & $\begin{array}{l}\text { (b) Give comments to the groups and use the multimedia to } \\
\text { show three different ways to count the candies. } \\
\text { The first way of putting candies altogether }\end{array}$ & \\
\hline & $\begin{array}{l}\text { There are } 24 \text { candies on the left, and then there are } 9 \\
\text { candies on the right. }\end{array}$ & \\
\hline & $\begin{array}{l}\text { Next, encourage students to investigate and move } 4 \text { candies } \\
\text { on the left and } 6 \text { candies on the right to 'making 10'. } \\
\text { Finally, } 30 \text { candies plus } 3 \text { candies equals } 33 \text { candies } \\
\text { altogether. }\end{array}$ & \\
\hline & The second way of putting candies altogether & \\
\hline & $\begin{array}{l}\text { There are } 24 \text { candies on the left, and then there are } 9 \\
\text { candies on the right. }\end{array}$ & \\
\hline & $\begin{array}{l}\text { Next, encourage students to investigate and move } 1 \text { candy } \\
\text { on the left and } 9 \text { candies on the right to 'making } 10 \text { '. } \\
\text { Finally, } 23 \text { candies plus } 10 \text { candies equals } 33 \text { candies } \\
\text { altogether. }\end{array}$ & \\
\hline & The third way of putting candies altogether & \\
\hline & $\begin{array}{l}\text { There are } 24 \text { candies on the left, and then there are } 9 \\
\text { candies on the right. }\end{array}$ & \\
\hline & $\begin{array}{l}\text { Next, encourage students to investigate and move } 4 \\
\text { candies on the left plus } 9 \text { candies on the right equals } 13 \\
\text { candies. Then, there is a 'making } 10 \text { ' in } 13 \text {. Finally, } 20 \\
\text { candies plus } 13 \text { candies equals } 33 \text { candies altogether. }\end{array}$ & \\
\hline
\end{tabular}

The three mentioned ways of 'putting candies altogether' hint at different ways of 'making 10':

- To increase 24 to 30 (3 tens).

- To increase 9 to 10 ( 1 ten).

- To decrease 24 to 20 ( 2 tens).

The teacher knew in advance that some students might have difficulties; hence, she was ready to encourage students, forcing the grouping strategy, using the concept of 'making 10'. 


\subsubsection{The Functioning in the Classroom}

The time planned for the solution was very short $(15 \mathrm{~min})$. However the students succeeded in solving the problem finding the three solutions anticipated by the teacher in a shorter time. The process may be outlined looking at the transcript (translated from Cantonese). The final solutions produced by the groups are in the figure of the Stage 3 .

00.00 Here you have some candies, we can count how many candies, each group has candies boxes. Put on the table and calculate. Think how to use the candies and find the result. You can split candies and move between the boxes on the left and on the right.

... Students work in small groups.

02.14 Have you finished? Good job! And you? Have you finished? And you? Good job!

02.32 Very fast! Very good!

02.39 Let's look together. Turn to this direction (the whiteboard).

$\ldots \quad$ The first solution: $24+9=23+(1+9)=33$

03.07 Let's look how she did. Hang to the board. Tell them how and why you did this way. To take away the group of 4 and put there. Why? I understand, in this way you have on the right the sum 10 , on the right is three groups of 10,30 , right? All together is 33 .

04.00 Do you have different methods? Did you think another way? Raise your hands. Did you think another way? Please, come here, carry your boxes.

... The second solution is given: $24+9=20+(4+9)=33$

06.05 Good job! Are there other methods? Have you thought in a different way?

... The third solution: $24+9=(24+6)+3=33$

08.03 Many solutions, many different solutions. Are there different solutions? How did you move the candies? This is the same as the first method. Other solutions? How did you do? It's the same. You also. Other solutions? Do you have other methods? Let me know.

09.00 In mathematics is there only one solution?

Voices No no no.

We may have many different solutions. Yes, you have made different solutions for this problem. To make the addition of a two-digit number and a one-digit number we may use different ways to group and move and get the same result.

Later ...

31.43 In mathematics is there only one solution? You may use any method, you have only to find the same result and you look for the fastest method.

(Electronic Supplementary Material: Sun 2017a, b)

It is worthwhile to observe how the teacher highlights the variation (one problem, multiple solutions (OPMS)) that seems to be the most important global message of the lesson, besides the technique of grouping-ungrouping. Variation of the 'making 10' solution is emphasised and reinforced in other episodes of the lesson, when other problems to be solved orally or in writing are given and are reconsidered at the end (min. 31.43). The coherence between the lesson plan and the realised interaction is very high. According to some scholars (Wang et al. 2015), 'recent international studies in mathematics education have identified a high degree of instructional coherence as a distinguishing feature in classrooms in China' (p. 112). The teacher's discourse showed a high degree of coherence throughout the lesson and, apparently, the students developed a sense of what was going on, showing choral answers to some questions. 


\subsubsection{A Short Summary}

In this section we have tried to give an insider perspective of an 'indigenous' pedagogical practice. The practice, namely, variation problems, is known widely in Chinese mathematics curricula as 'one problem, multiple solutions' (OPMS, 一題 多解, varying solutions), 'one problem, multiple changes' (OPMC, 一題多變, varying conditions and conclusions) and 'multiple problems, one solution' (MPOS, 多 題一解, varying presentations). We have seen examples of the first two above. A more comprehensive summary of this kind of variation problems is in Chap. 3. A complete discussion and comparison with Marton's variation theory is in Sun (2011b). Variation practice aims at abstracting and generalising, focusing on relationships between numbers rather than on arithmetic operations. This is consistent with the aim of developing algebraic thinking (Cai 2004; Sun 2016). This 'indigenous' pedagogical practice has clear boundaries that allow one to uncover how variation practice has been and is now used in Chinese classrooms and a true operational effectiveness that might be used to transpose it to other contexts (Bartolini Bussi et al. 2013). An example of transposition from China to Italy is discussed in this volume (Chap. 3).

\subsubsection{A Westerner's Perspective: Marton's Variation Theory}

It must be emphasised that the following account is a particular 'reading' of the lesson and in particular a reading of deliberate intent behind the selection and structuring of the examples offered to the students to consider. Such a post hoc interpretation is not meant to be 'reading the mind' of the teacher - it could well be that the actual rationale behind the choice of examples bears no resemblance to the interpretation presented here. The intent, however, is not to definitively pronounce what was behind the design of the lesson, but to use the lesson as a starting point for thinking about lesson design and how variation theory (in the sense developed by Ference Marton) might be helpful in designing lessons that provide sound opportunities for learning whole number arithmetic and inform the conversation on what mathematical knowledge for teaching needs to be brought to lesson design.

The starting point is the definition of an exercise as put forward by Watson and Mason (2006a), that is, an exercise is 'a collection of procedural questions or tasks'. Thus, rather than examining the separate questions that learners work on in a lesson, these are collectively regarded as contributing towards a set, an exercise, that may be more or less mathematically and pedagogically structured. Thus, the lesson observed had as a major exercise a number of discrete questions all based around adding a single digit to a two-digit number and that the selection, ordering and ways of working within this exercise led to a coherence in the lesson that amounted to more than the sum of the parts.

To examine this, two particular episodes in the lesson are looked at in detail: the working on the problem of 24 sweets plus 9 sweets and the sequence of calculations 
where learners chose their own two-digit number to work with. Central to this analysis is an exploration both of how the teacher worked with highly interrelated example sequences (Watson and Mason 2006a) and of the ways of simultaneously working with horizontal relationships within examples and vertical patterns between examples (Watson and Mason 2006b).

\subsubsection{Variation Theory}

Variation theory (VT) as developed by Ference Marton and colleagues (Marton et al. 2004) is a theory of learning, not an all-encompassing theory of pedagogy. VT, for example, sheds no light on whether group work is better than individual work or whether physical materials are more useful than pictures or images, although VT theorists acknowledge that these other features of the learning environment are important. The overall aim of VT as developed by Marton and colleagues is to attend to aspects of learning that focus on the specific mathematical content, distinguishing VT from other theories of learning that provide accounts of how learning occurs that are independent of what actual content is expected to be learnt. As a group of teachers and researchers in Hong Kong engaged in 'learning studies' that draw on VT to look at how diverse classroom communities can learn particular content note:

Contrary to the belief of some educational theorists, therefore, we believe that one simply cannot develop thinking in isolation from the objects of thought. Learning is always the learning of something, and we cannot talk about learning without paying attention to what is being learnt. (Lo et al. 2005, p. 14)

It is beyond the scope of this chapter to go into all the details of VT, but central to the argument here are the constructs of objects of learning, discernment and variation.

VT acknowledges the intentionality of teaching: teaching is always directed towards specific learning ends or, in the language of VT, objects of learning. An object of teaching is never unitary: any teaching activity is always, and inevitably, directed towards at least two objects of learning. There is the direct object of learning - in this lesson, the addition of two numbers. It is this that learners are usually most focused upon as revealed through their answers to the question, 'What did you learn today'? Answer: 'How to add'. But every teaching activity also encompasses one or more general capabilities that are broader than the specific object of learning, for example, interpreting or generalising. These comprise the indirect object of learning (Marton et al. 2004).

According to Bowden and Marton (1998), our learning is a result of what we are able to discern, distinguish. But we can only distinguish between things when there is variation in our experiences:

When some aspect of a phenomenon or an event varies while another aspect or other aspects remain invariant, the varying aspect will be discerned. In order for this to happen, variation must be experienced by someone as variation. (Bowden and Marton 1998, p. 35) 
Variation is the key to being able to discern. As Watson and Mason (2006a) argue, any aspect of a task or situation that it is hoped learners will discern (the lived object of learning) 'is more likely to be discerned if its variation is foregrounded against relative invariance of other features' (p. 98). In other words, what is not varied is as important to attend to as what is varied. So the teacher is in control of the 'enacted object of learning' through the structuring of the 'example space' (Watson and Mason 2005), that is, a collection of examples that fulfil a specific function (Zazkis and Leikin 2007). And equally, if too much is varied, then either nothing may be discerned or inappropriate or irrelevant features attended to. As Runesson (2005, p. 72) notes, 'studies have shown that exposure to variation is critical for the possibility to learn, and that what is learnt reflects the pattern of variation that was present in the learning situation'.

\subsubsection{Variation Within the Lesson}

The first example in the exercise of adding a single digit to a two-digit number with carrying in the main teaching part of the lesson was based around the party time problem of adding 9 sweets to 24 sweets. Groups of learners were given 24 candies as two full boxes of ten and a box with only four, together with a box of nine. As the groups worked on solving the problem practically, the teacher roamed around noting the different methods and selecting which groups she was going to invite to share their approach with the class. As noted in the account, the teacher had already prepared posters for three strategies and so was, presumably, looking for groups whose strategy fitted with what she had anticipated.

Each group asked to demonstrate their solution started by putting up on the board the two boxes of ten and the four units and the box of nine to the right of these and modelling with the candies what they had done. In this way, three different partitionings of one of the numbers was elicited: partitioning the 24 into $23+1$ and effectively doing $24+9=(23+1)+9=23+(1+9)=23+10$ (although recorded differently, but consistently across the three solutions, by the teacher). Similarly, there was $24+9=(20+4)+9=20+(4+9)=20+13$ and $24+9=24+(6+3)$ $=(24+6)+3=30+3$.

Here in one example we see careful variation and non-variation. What was kept constant was the calculation and the partitioning of one of the numbers in a way that anticipated creating a multiple of ten to be added to another number. Thus, while the direct object of learning was to calculate the sum, indirect objects implicitly worked with included the associative rule for addition, equivalence and the simplifying of calculations by creating a multiple of ten. All of this, we suggest, was enacted through carefully working horizontally within one example and carefully determined variation within this horizontal working. So while it might be argued that the teacher, in predetermining the solution methods that she sought, limited the opportunity for attending to other things such as learner creativity, from a VT perspective, the control exercised by the teacher here is central to directing what might be discerned by the learners. 
The next set of examples in the exercise that we want to examine is the sequence where learners used digit cards to make their own two-digit number. While the teacher made some play of appearing to randomly select a digit for them to add to their number, it seemed from her actions that the pulling out of 9 was not entirely random. Again, as the learners were working, the teacher moved around and chose three to come and show, now using a visualiser, their working (recreating this, not simply showing the final working). The fact that the third example $-95+9-$ drew gasps of delight from the class suggests again that the choice and sequencing of the three children invited to share their solutions were carefully considered by the teacher. From the perspective of VT, what was now varied was the choice of twodigit number, but adding 9 (and subsequently 7) kept constant. The choice of 9 again not only, in being close to ten, may have encouraged attention to making a multiple of ten, but also only made a small vertical move from the three methods of adding $24+9$ still displayed on the board. Thus, learners were encouraged to attend to how they can build on what they have just done, rather than having to deal immediately with both numbers being varied.

So although this lesson can be read as being very tightly controlled by the teacher, that control can be read as located in a carefully thought out exercise, a carefully constructed example space, designed to help learners develop effective methods of calculating.

\subsubsection{Comparison}

When comparing the two approaches to variation theory presented in Sects. 11.4.1 and 11.4.2, there are many similarities. But there can also be found substantial differences, the roots of which can be briefly summarised as follows: Marton's theory is a theory of learning (Kullberg 2010), while indigenous variation practice is a method of task design for teaching. More information about variation theory can be found in Chap. 3. A comprehensive book on teaching with variation has been published by Huang and Li (2017).

\subsection{View Through the Lenses of the Theory of Didactical Situations}

One efficient tool for analysing teaching episodes is Brousseau's (1997) theory of didactical situations (TDS). In TDS, two different types of knowledge are distinguished: connaissance (a knowing) and savoir (knowledge). In the text of this section, we use the English translations of the French terms introduced in Brousseau (1997, p. 72, Editors' note): 'The former refers to individual intellectual cognitive constructs, more often than not unconscious; the latter refers to socially shared and recognised cognitive constructs, which must be made explicit'. 


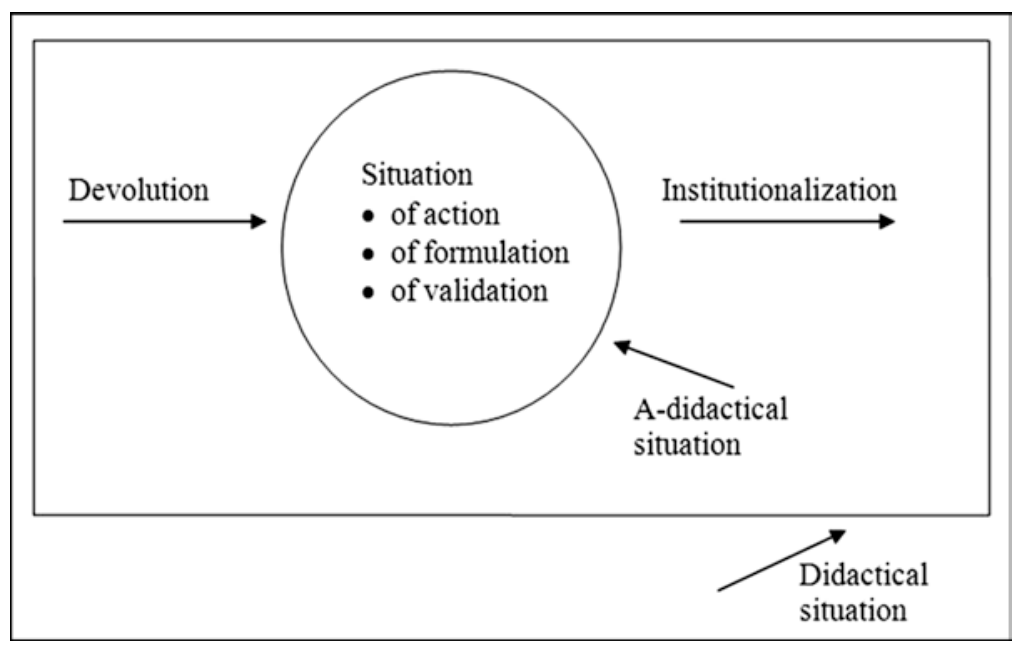

Fig. 11.13 Scheme of a didactical situation

\subsubsection{Didactical Situations}

Let us summarise the main characteristics of a didactical situation as used in TDS (Brousseau 1997; Brousseau and Sarrazy 2002). In didactical situations, the teacher organises a plan of action which makes clear her intention of modifying or causing the creation of some knowledge for the student, for example, and which permits her to express herself in actions. Certain didactical situations, the so-called a-didactical situations, are (intentionally) partially liberated from the teacher's direct interventions. An a-didactical situation is the autonomous part of an individual or collective activity of students; and student's adaptation to this situation shows the knowing involved.

The theory classifies situations according to their structure (action, formulation, validation, etc.) which determines different types of knowledge (implicit models, languages, theorems, etc.). Figure 11.13 schematically records the structure of a didactical situation.

The a-didactical situation of action is a situation in which a knowing is manifested only by decisions and by regular and effective actions on the milieu ${ }^{1}$ and where it is of no importance to the evolution of the interactions with the milieu whether the actor can or cannot identify, make explicit or explain the necessary knowing.

The a-didactical situation of formulation puts at least two actors into relationship with the milieu. Their common success requires that one of them formulates the knowing in question for the use of the other, who needs it in order to convert it to an effective decision about the milieu.

The a-didactical situation of validation is a situation whose solution requires that the actors establish together the validity of the characteristic knowledge of this situation.

\footnotetext{
${ }^{1}$ The word 'milieu' denotes everything which acts on the student and/or on which she acts.
} 
The institutionalisation of a knowing reveals itself by the passage of this knowing from its role as a means of resolving a situation of action, formulation or validation to a new role, that of reference for future personal or collective uses and, thus, as a piece of knowledge.

Devolution is the process by which the teacher manages in an a-didactical situation to put the student in the position of being a simple actor in an a-didactical situation.

\subsubsection{Elements of Didactical Situations in the Lesson}

For tracing the features of TDS in the lesson, let us analyse Stage 3 (group counting and sharing: addition with two-digit numbers and one-digit number with regrouping ones). It followed the stage during which children got acquainted with a scheme describing adding two numbers without regrouping (Fig. 11.14).

The objective of Stage 3 was represented by adding $24+9$. The expected activity was explained by the teacher on the interactive board in front of the classroom. Tens were represented by a box with ten rounds in a rectangle. Therefore 24 and 9 occurred as the scheme on Fig. 11.15 (devolution).
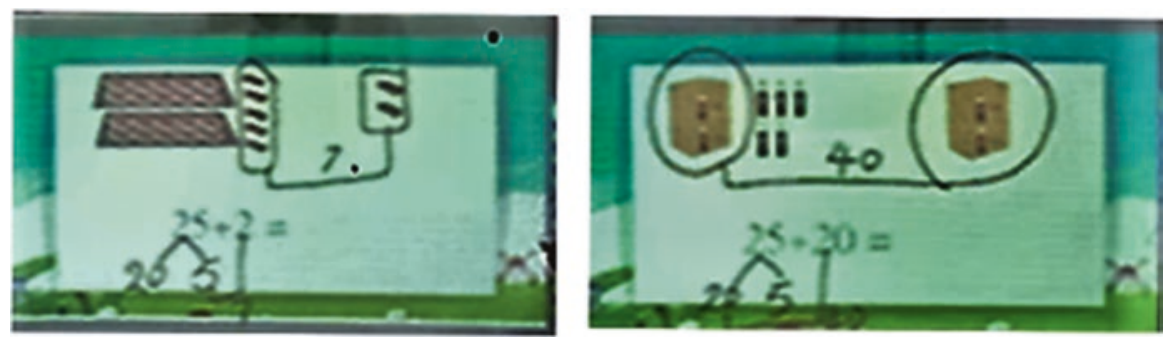

Fig. 11.14 Representations on the whiteboard

Fig. 11.15 Representation of 24 and 9

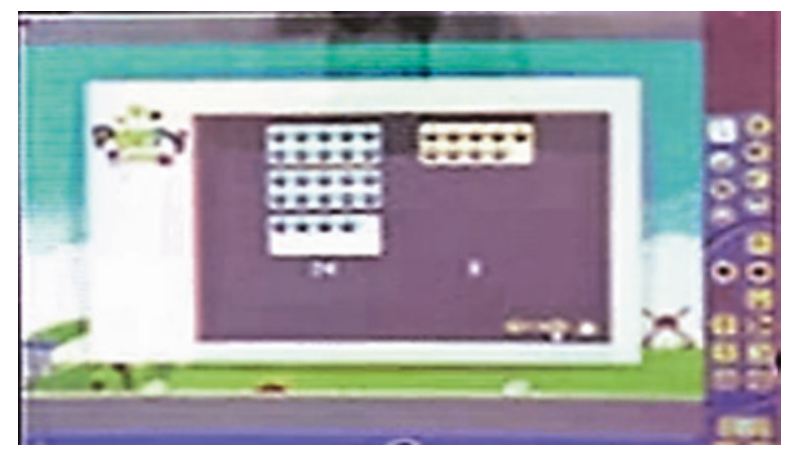


Fig. 11.16 Candies in boxes
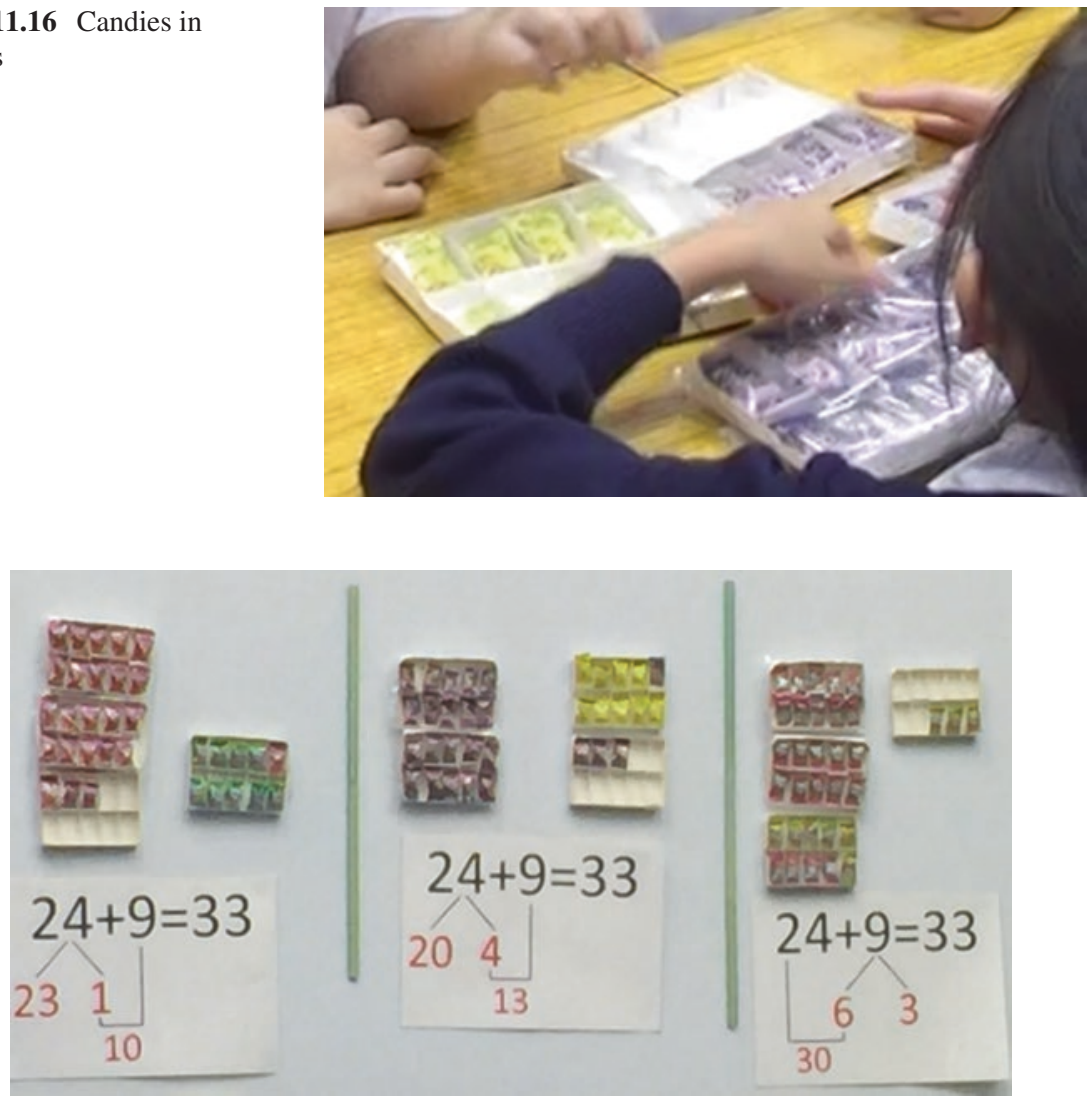

Fig. 11.17 Different representations of $24+9$

Students worked in groups. They were provided with boxes for ten candies. Twenty-four violet candies were placed in two full boxes and the third box contained four candies and six empty slots (Fig. 11.16). In another box, nine yellow candies were stored. When looking for the sum, students tried to add more candies in one box that was not full to have complete it to ten candies (of candies of both colours). Thus, there are three valid procedures to deal with the boxes (see Fig. 11.7). The teacher circulated through the classroom and recorded procedures applied by individual groups. From time to time, she interfered in the work of a group. By acting, students built the knowing of regrouping for the addition of $24+9$. The a-didactical part of the situation is rather limited and does not offer too much freedom for students to act in relationship with the milieu (even filling in the boxes is already predetermined by providing groups with the given number of boxes and placing candies in a certain way in them).

The formulation and validation of the developed knowing were organised together as a whole class activity managed by the teacher. She asked representatives of groups to come to the front and model their procedure with the boxes of candies 
they used. At the same time, she projected a schematic description of the presented procedure and added the symbolic record of the solving strategy under the boxes fastened on the board (Fig. 11.17).

Institutionalisation was realised in the form of solving similar problems. This time, students worked in their exercise books. Individual students presented then their calculations (projected their record and explained it). The teacher did not finish with the presentation of one procedure but elicited the occurrence of others. She pushed children to work as fast as possible (the speed of solving looks to be an important factor in Chinese classrooms). The teacher insisted on students' independent description and explanation of each step of their solving procedure.

The process from the work with models to the 'abstract' way of solving the problem using mathematical symbols showed to be smooth and understandable for students.

\subsection{Classroom Assessment in Whole Number Arithmetic}

Mathematics teachers need to assess their students' learning progress in whole number arithmetic to be able to provide pertinent guidance during the learning process. Not only is this knowledge necessary, it is even impossible to teach without it, because teachers' teaching should build on and link to what the students already know. In other words, teachers need to have insight into students' solution strategies reflecting their mathematical thinking (Gearhart and Saxe 2005). The guidance teachers provide in their mathematics classes can be more or less effective for stimulating students' understanding, depending on whether their instruction is attuned to students' needs and possibilities for further development (cf. Butterworth 2015: '[g]etting the correct assessment is fundamental for selecting the appropriate intervention' (p. 28)). In a continual striving for providing the best possible explanations to students, teachers need to know at practically every particular moment in their classes of every single student where they are in their understanding. This echoes Schoenfeld (2014) statement that, '[p]owerful instruction 'meets students where they are' and gives them opportunities to move forward' (p. 407). Teachers can acquire insight about students' whole number arithmetic abilities by qualitative and holistic assessments, such as observing students in class and giving them openended tasks, providing a reliable window for knowing students' progress (cf. Black 2014). Taking this formative perspective in assessment offers teachers the possibility to adequately assess students' understanding in such a way that it directly informs their teaching of whole number arithmetic. Teachers can use the results of such formative classroom assessment to make instructional decisions, for example, to decide whether they need to adapt instruction to fit students' current mathematical understanding, repeat a particular exercise or explanation or, if students have reached a satisfactory insight, continue with their previously planned further instruction. This type of assessment is completely in 'the hands of teachers' (van den Heuvel-Panhuizen and Becker 2003, p. 683). 


\subsubsection{Reflection on the Possible Assessment Fragment of the Lesson in Macao}

During the lesson observed in Macao there were some instances where the teacher appeared to be assessing her students' skills; she did not, however, seem to make formative use of the information that she could gather from the students' responses. The lead-in stage of the lesson could have functioned as a formative assessment technique, in the sense that through the students' answers to the different number combinations of 10 the teacher could have found out whether the students had memorised these number facts. Subsequently, she could have used this information to decide how to proceed with her further instruction. Checking students' knowledge of the combinations of 10 , as she did in this lesson, is a very insightful starting point, as this understanding/knowledge is a prerequisite underlying the more complex calculations that were planned later in this lesson, i.e. addition with regrouping (crossing 10) until 100. However, as a formative assessment technique, it could have provided only limited useful information, as merely confirmatory evidence was gathered: all the different combinations were provided, ordered from $9+1,8+2$, etc. to $2+8,1+9$ and $10+0$. Students had to write, as fast as possible, the result of every 'calculation', i.e. 10, next to each member of the list of combinations. Evidently, this can be done in several ways, of which only one really concerns the use of previously memorised number facts. Other solution strategies are, for example, the recognition of the minor variation in the problems, and thus concluding that all answers must be 10, without calculating, or calculating all of the combinations one by one, but fairly quickly, as they are, even for Grade 1 students, relatively easy. As a fun exercise - it was a timed competition where students could register their elapsed time themselves - this activity had its merits, but it could possibly have been more informative if it were used by the teacher with a formative assessment purpose in mind. For this, to inform further instruction, it would not be necessary to neglect the memorisation and speed objectives of the calculation competition, but it would be necessary for the teacher to change her perspective from teaching or testing for the correct answer to assessing with the purpose of better adjusting her further teaching to her students' skills, level of understanding and knowledge of number facts.

\subsubsection{Alternative Lead-in Activity by Using Classroom Assessment}

An alternative task that could be used as a classroom assessment technique in this same context is the following. To find out if students really have learned the combinations of 10 and memorised them as number facts, an informative and interactive technique could be the classroom activity in which all the students have a red and a 
green card with which they can show their (dis)agreement with a series of statements. The statements can be 'Are these numbers together more than 10, yes (green) or no (red)? 2 and 7, 5 and 4...' and so on, to which all the students respond instantaneously by showing a red or green card (see, for experiences with such an assessment technique in third grade in the Netherlands, Veldhuis and van den Heuvel-Panhuizen 2014, and, for the effects on student achievement, Veldhuis and van den Heuvel-Panhuizen 2015). This classroom assessment technique immediately provides the teacher with an overview of students' understanding, not only about the correctness or speed of their answers, but also whether they are able to show their answers without hesitation or if they change their minds when looking at the cards their peers show (peer feedback). Also, through the interactive nature of this activity, room for a classroom discussion on strategies students used to decide on their agreement with the statements is created, as such enabling the teacher to provide feedback on these to the students. A further possibility provided by this assessment technique is the opening for further investigation, in the same way, of students' understanding or knowledge of the analogous combinations of 100 or even 1000. Through this, the teacher could become more assessment aware, meaning that she could distinguish students practising from assessing them. With only this slight adaption of the lead-in activity and the teacher using a formative assessment perspective, she could have adjusted her instruction to the students' needs even more than she already did. A different approach, focusing more on individual students, without changing the lead-in stage, is of course also possible. Such an approach was used in Australia (Gervasoni and Parish 2015) where teachers perform clinical individual assessment interviews. These interviews can provide valuable additional information on students' instructional needs in whole number arithmetic. Likewise, the Journal of Number (Sensevy et al. 2015), in which individual students are regularly prompted to write down what they know about the mathematics they encountered in the preceding lessons, could be used to further enlighten the teacher about her students' understanding.

\subsubsection{Classroom Assessment and the Lesson Plan}

For the teacher to use the gathered assessment information formatively, she would need to be flexible in the use of her lesson plan. When comparing the pre-established lesson plan to the lesson we observed, there appears to be a one-to-one correspondence in content, order and type of activities she proposed. Everything was very well prepared, from the concrete materials, the posters on the whiteboard, until the hidden answers to the different problems on the video-projected slides. The questions the teacher posed appeared to be mainly focused on steering the students' responses in the direction of the prepared materials. All problems the students had to solve clearly had one, and only one, correct response. This was remarkably exemplified by the way the teacher uncovered the correct responses to the exercises; the correct answers were hiding in the presentation slides, clearly predetermined and 
appeared not to be open for discussion. As such, the teaching and learning were deterministic, focused on getting the only right answer and not really open for different interpretations of the problems and different solutions. In South Africa, comparable teacher behaviour in the teaching of whole number arithmetic, consisting of mostly ignoring incorrect answers and rarely juxtaposing correct and incorrect answers, has also been observed (Ekdahl and Runesson 2015). Such an approach is quite reasonable for a scripted demonstration lesson, but is contrary to the idea of formative assessment in which lesson plans are necessarily adaptable, because the information the teacher collects about students' understanding is used to adjust the actual teaching following the assessment. The use of lesson plans in this observed Macao lesson reflects a recent finding in Nanjing, China (Zhao et al. 2015), in which Chinese mathematics teachers' lesson plans on division prevailed over the possible influence of newly gathered information on students' understanding. These Chinese teachers did use (formative) classroom assessment techniques, but seemed to be unable to divert from their lesson plans and as such did not use the assessment information formatively.

\subsection{The Role of Textbooks Related to Teaching of WNA}

Researchers have generally agreed that textbooks play a dominant and direct role in what is addressed in instruction. Robitaille and Travers (1992) noted that a great dependence upon textbooks is 'perhaps more characteristic of the teaching of mathematics than of any other subject' (p. 706). This is due to the canonical nature of the mathematics curriculum. Teachers' decisions about the selection of content and teaching strategies are often directly set by the textbooks they use (Freeman and Porter 1989; Reys et al. 2004). Therefore, textbooks are considered to determine largely the degree of students' opportunity to learn (OTL) (Schmidt et al. 1997; Tornroos 2005). This means that if textbooks implementing a specific curriculum differ students will get different OTL (Haggarty and Pepin 2002). Consequently, different student outcomes result, as confirmed by several studies which found a strong relation between the textbook used and the mathematics performance of the students (see, e.g., Tornroos 2005; Xin 2007).

There is no doubt about the influence of textbooks on teachers' practices related to the teaching of WNA in the primary school. Knowledge about approaches to teach WNA presented in textbooks in different educational systems can provide deep insights about the diverse ways of how WNA is taught. The WNA curriculum varies across educational systems. The degree of coupling of the intended curriculum presented in textbooks with the prescribed curriculum in official documents also varies across educational systems in the world. For example, in Mainland China (Ni 2015) and Singapore (Kaur 2015), textbooks and the corresponding teaching materials are the most important vehicles used to implement the nationally mandated curriculum. The development and publishing of textbooks is closely regulated and monitored by the central government, the Ministry of Education, and there are 
only a few officially designated publishers who are allowed to develop textbooks and teaching manuals. However, this is not the case in some countries like the Netherlands (van Zanten and van den Heuvel-Panhuizen 2014) and France (Chambris 2015), where the respective governments only prescribe the content to be taught and publishers are left to develop textbooks without any restrictions. Likewise, in Australia and Germany, the curriculum is set by the states and follows a framework agreed by all the states, and textbooks are developed by publishers without any involvement of the authorities who prescribe the curriculum (PeterKoop et al. 2015). At times, when publishers are left to produce the books with no guidance, a mismatch may occur, as Yang (2015) found that although the national curriculum in Taiwan emphasises number sense, few activities related to number sense are found in the elementary textbooks.

Furthermore, in some educational systems, teachers do use textbooks more often than others. In most countries where education authorities are involved in the production of the textbooks, e.g. Singapore (Kaur 2015), Hong Kong SAR (Zhang et al. 2015) and China (Cao et al. 2015), teachers use textbooks in teaching the WNA curriculum in the elementary grades. In other systems, for example, Australia, there may be a variety of textbooks used in the schools, but it is also common for teachers not to use a textbook at all, but rather devise their own tasks or draw on a variety of resources, including textbooks. In Germany, the vast majority of the teachers use one of the major textbooks, available for primary schools, to teach WNA (Peter-Koop et al. 2015). The same is true for Thailand (Inprasitha 2015). Changsri (2015) and Inprasitha (2015) noted that the use of textbooks that consist of mainly routine exercises, by teachers in Thailand, may be the cause of poor performance of Thai students in mathematics.

It is inevitable that cultural and traditional perspectives are present in textbooks for the teaching of WNA. In China, the 同文算指 Tongwen Suanzhi (a treatise compiled by a Chinese scholar Li Zhi-zao and an Italian Jesuit Matteo Ricci) has had significant influence on the teaching and learning of arithmetic and pedagogical design of textbooks (Siu 2015). Likewise, the number line as found in textbooks appears to be a Western aid for teaching WNA, as traces of its use can be found in the early teaching practices of most Western countries (Bartolini Bussi 2015).

The teaching of WNA has evolved with time and this is clearly evident from textbooks. In France, the classical theory of numbers which was adapted in close terms in textbooks disappeared from the textbooks and teacher books for teacher education during the 1980s (Chambris 2015). In Singapore, since the 1980s, textbooks have adopted the concrete-pictorial-abstract approach for the learning of WNA. In addition, the model method - a tool for representing and visualising relationships - has been a key heuristic students use for solving whole number arithmetic (WNA) word problems (Kaur 2015).

Comparative studies of textbooks, both within and between countries, have also shed light on the depth and breadth of the WNA curriculum across the world. Zhang et al. (2015) found that the four sets of textbooks they studied in Hong Kong followed the same curriculum guide for the design of the teaching units, and therefore 
there were only subtle differences in the structure and sequencing of content for two-digit subtraction of numbers in the books. However, van Zanten and van den Heuvel-Panhuizen (2014) in their study of two Dutch textbook series found that the textbook series reflected divergent views on subtraction up to 100 as a mathematical topic, which were subtraction up to 100 bridging a ten and subtraction up to a 100 without bridging a ten. The research by Inprasitha (2015) and Changsri (2015) on the teaching of WNA in Thai schools, adopting the Lesson study and open approach using Japanese mathematics textbooks, show how the Japanese textbooks are influencing the curriculum materials and teaching approaches for the teaching of WNA in classrooms of Thailand. Alafaleq et al. (2015) found that generally there was a high level of uniformity in the way the comparison of whole numbers was introduced in textbooks in China, Indonesia and Saudi Arabia.

Lastly, textbooks too may have their weaknesses. At times, they use notations that give rise to erroneous conclusions. For example, Cooper (2015) noted that in Israel elementary mathematics textbooks when 25 was divided by 3 , the result 8 remainder 1 was written as $8(1)$, that is, $25: 3=8(1)$. Similarly, when 41 was divided by 5 , it was written as $41: 5=8(1)$. This leads to a nonsensical deduction that $25: 3=41: 5$. Cooper suggests that if the notation was revised as $25: 3=8(1: 3)$, it would circumvent any wrong conclusions of the equivalence relationship. Textbooks also tend to treat topics as isolated units with little connection to other units (Sowder et al. 1998). Shield and Dole (2013) found that often textbooks show the algorithmic way that topics requiring proportional reasoning are addressed with little or no connection made to related topics such as decimals, ratio, proportion and percent.

The limited focus on the connections between topics inside as well as outside mathematics and the emphasis on algorithms, closed answer form and simple connections in textbooks are hot topics addressed in many documents. For example, findings in several contributions at the International Conference on Mathematics Textbook Research and Development 2014 (ICMT-2014) highlighted this problem; see, e.g. Veilande (2014) who in his comparative study of WNA problems in Latvian fifth grade mathematics textbooks and the same in Mathematics Olympiads found that generally textbook problems focused on mathematical operations and understanding, while Olympiad problems on properties and mathematical thinking. The presentation and solving of problems in textbooks has also been the main topic of the work carried out by the Nordic Network of Research on Mathematics Textbooks (Grevholm 2011).

\subsection{Concluding Remarks}

The teaching and assessing of WNA is a relatively large domain. It is not possible to cover all its aspects in a chapter. Therefore, it was necessary to select some aspects which may be addressed, as we have done in this chapter. 
The choice of lenses used in this chapter was guided by several aspects: the main focus was formulated in the Discussion Document (this volume, Appendix 2) and represents the agreement of all the IPC members. The second strong influence was the development of the debates in Theme 4 sessions at the ICMI Study 23 Conference in Macao, the richness of which is documented in the survey of contributions at the beginning of this chapter. The third was the decision of the team of authors to develop ideas that emerged from the lesson that they observed in Macao as part of the conference. The purpose of using the lesson to contextualise the discussion in this chapter on aspects of teaching and assessing WNA was not to critique any particular approach nor use of resource of the lesson, but rather to show how the lesson may be interpreted using various theoretical and methodical frameworks.

\section{References}

Bartolini Bussi, M. G., \& Sun, X. (2015). Learning from the world: The teaching and learning of whole numbers arithmetic in the ICMI study 23. In Copirelem (Ed.), Actes du 42e Colloque International des formateurs de mathématiques chargés de la formation des maîtres (pp. 39-51). Besancon: ARPEME.

Bartolini Bussi, M. G., Sun, X., \& Ramploud, A. (2013). A dialogue between cultures about task design for primary school. In C. Margolinas (Ed.), Task design in mathematics education. Proceedings of ICMI study 22 (pp. 549-558). UK: Oxford. Retrieved February 10, from https:// hal.archives-ouvertes.fr/hal-00834054v3.

Black, P. (2014). Assessment and the aims of the curriculum: An explorer's journey. Prospects, 44(4), 487-501.

Bobis, J., Clarke, B., Clarke, D., Thomas, G., Wright, R., Young-Loveridge, J., \& Gould, P. (2005). Supporting teachers in the development of young Children's mathematical thinking: Three large scale cases. Mathematics Education Research Journal., 16(3), 27-57.

Bowden, J., \& Marton, F. (1998). The university of learning. London: Kogan Page.

Brousseau, G. (1997). Theory of didactical situations in mathematics 1970-1990 (F. M. Cooper, N. Balacheff, R. Sutherland \& V. Warfield, Trans.). Dordrecht: Kluwer Academic Publishers.

Brousseau, G., \& Sarrazy, B. (2002). Glossaire de quelques concepts de la théorie des situations didactiques en mathématiques (V. Warfield, Trans.). Bordeaux: DAEST, Université Bordeaux 2.

Bruner, J. S. (1960). The process of education. Cambridge, MA: Harvard University Press.

Cai, J. (2004). Developing algebraic thinking in the earlier grades: A case study of the Chinese elementary school curriculum. The Mathematics Educator, 8(1), 107-130.

Clarke, D., Cheeseman, J., Gervasoni, A., Gronn, D., Horne, M., McDonough, A., Montgomery, P., Roche, A., Sullivan, P., Clarke, B., \& Rowley, G. (2002). Early numeracy research project final report. Melbourne: Australian Catholic University.

Clements, M. A., \& Ellerton, N. (1995). Assessing the effectiveness of pencil-and-paper tests for school mathematics. In B. Atweh \& S. Flavel (Eds.), Galtha: Proceedings of the 18th annual conference of the Mathematics Education Research Group of Australasia (pp. 184-188). Darwin: Northern Territory University.

Freeman, D., \& Porter, A. (1989). Do textbooks dictate the content of mathematics instruction in elementary schools? American Educational Research Journal, 26(3), 403-421.

Gearhart, M., \& Saxe, G. B. (2005). When teachers know what students know. Theory Into Practice, 43(4), 304-313.

Gervasoni, A., Parish, L., Hadden, T., Turkenburg, K., Bevan, K., Livesey, C., \& Croswell, M. (2011). Insights about children's understanding of 2-digit and 3-digit numbers. In J. Clark, 
B. Kissane, J. Mousley, T. Spencer, \& S. Thornton (Eds.), Mathematics: Traditions and [new] practices. Proceedings of the 23rd biennial conference of the Australian Association of Mathematics Teachers and the 34th annual conference of the Mathematics Education Research Group of Australasia (Vol. 1, pp. 315-323). Alice Springs: MERGA/AAMT.

Gervasoni, A., \& Sullivan, P. (2007). Assessing and teaching children who have difficulty learning arithmetic. Educational \& Child Psychology, 24(2), 40-53.

Grevholm, B. (2011). Network for research on mathematics textbooks in the Nordic countries. Nordic Studies in Mathematics Education, 16(4), 91-102.

Haggarty, L., \& Pepin, B. (2002). An investigation of mathematics textbooks in England, France and Germany: Some challenges for England. Research in Mathematics Education, 4(1), $127-144$.

Huang, R., \& Li, Y. (2017). Teaching and learning mathematics through variation. Confucian heritage meets Western theories. Rotterdam: Sense Publishers.

Kullberg, A. (2010). What is taught and what is learned. Professional insights gained and shared by teachers of mathematics. Göteborg studies in Educational sciences no 293. PhD thesis, Acta Universitatis Gothoburgensis, Göteborg.

Lo, M. L., Pong, W. Y., \& Chik, P. P. M. (Eds.). (2005). For each and everyone: Catering for individual differences through learning studies. Hong Kong: Hong Kong University Press.

Marton, F., Tsui, A. B. M., Cjik, P. P. N., Ko, P. Y., \& Lo, M. L. (2004). Classroom discourse and the space of learning. Mahwah: Lawrence Erlbaum Associates.

Mitchell, A., \& Horne, M. (2011). Listening to children's explanations of fraction pair tasks: When more than an answer and an initial explanation are needed. In J. Clark, B. Kissane, J. Mousley, T. Spencer, \& S. Thornton (Eds.), Mathematics: Traditions and [new] practices. Proceedings of the 23rd biennial conference of the Australian Association of Mathematics Teachers and the 34th annual conference of the Mathematics Education Research Group of Australasia (Vol. 1, pp. 515-522). Alice Springs: MERGA/AAMT.

Murata, A., \& Fuson, K. (2006). Teaching as assisting individual constructive paths within an interdependent class learning zone: Japanese first graders learning to add using 10. Journal for Research in Mathematics Education, 37(5), 421-456.

Reys, B. J., Reys, R. E., \& Chávez, O. (2004). Why mathematics textbooks matter. Educational Leadership, 61(5), 61-66.

Robitaille, D. F., \& Travers, K. J. (1992). International studies of achievement in mathematics. In D. A. Grouws (Ed.), Handbook of research on mathematics teaching and learning (pp. 687709). New York/Reston: Macmillan/National Council of Teachers of Mathematics.

Runesson, U. (2005). Beyond discourse and interaction. Variation: A critical aspect for teaching and learning mathematics. Cambridge Journal of Education, 35(1), 69-87.

Schmidt, W., McKnight, C., \& Raizen, S. (1997). A splintered vision: An investigation of U.S. science and mathematics education. Boston: Kluwer Academic Publishers.

Schoenfeld, A. H. (2014). What makes for powerful classrooms, and how can we support teachers in creating them? A story of research and practice, productively intertwined. Educational Researcher, 43(8), 404-412.

Selter, C. (1998). Building on children's mathematics: A teaching experiment in grade three. Educational Studies in Mathematics, 36(1), 1-27.

Shield, M., \& Dole, S. (2013). Assessing the potential of mathematics textbooks to promote deep learning. Educational Studies in Mathematics, 82(2), 183-199.

Sowder, J., Armstrong, B., Lamon, S., Simon, M., Sowder, L., \& Thompson, A. (1998). Educating teachers to teach multiplicative structures in the middle grades. Journal of Mathematics Teacher Education, 1(2), 127-155.

Steffe, L., Cobb, P., \& von Glasersfeld, E. (1988). Construction of arithmetical meanings and strategies. New York: Springer-Verlag.

Sullivan, P., Askew, M., Cheeseman, J., Clarke, D., Mornane, A., Roche, A., \& Walker, N. (2015). Supporting teachers in structuring mathematics lessons involving challenging tasks. Journal of Mathematics Teacher Education, 18(2), 123-140. 
Sun, X. (2011a). An insider's perspective: "variation problems" and their cultural grounds in Chinese curriculum practice. Journal of Mathematical Education, 4(1), 101-114.

Sun, X. (2011b). "Variation problems" and their roles in the topic of fraction division in Chinese mathematics textbook examples. Educational Studies in Mathematics, 76(1), 65-85.

Sun, X. (2016). Spiral variation: A hidden theory to interpret the logic to design mathematics curriculum and instruction in Mainland China (in Chinese). Singapore: World Scientific Publishing Company.

Sun, X., Neto, T. B., \& Ordóñez, L. E. (2013). Different features of task design associated with goals and pedagogies in Chinese and Portuguese textbooks: The case of addition and subtraction. In C. Margolinas (Ed.), Task design in mathematics education. Proceedings of ICMI study 22 (pp. 409-418). Oxford. Retrieved February 10, from https://hal.archives-ouvertes.fr/ hal-00834054v3.

Tornroos, J. (2005). Mathematics textbooks, opportunity to learn and student achievement. Studies in Educational Evaluation, 31(4), 315-327.

van den Heuvel-Panhuizen, M., \& Becker, J. (2003). Towards a didactical model for assessment design in mathematics education. In A. J. Bishop, M. A. Clements, C. Keitel, J. Kilpatrick, \& F. K. S. Leung (Eds.), Second international handbook of mathematics education (pp. 689716). Dordrecht: Kluwer Academic Publishers.

van den Heuvel-Panhuizen, M., \& Drijvers, P. (2014). Realistic mathematics education. In S. Lerman (Ed.), Encyclopedia of mathematics education (pp. 521-525). Dordrecht/Heidelberg/ New York/London: Springer.

van Zanten, M., \& van den Heuvel-Panhuizen, M. (2014). Freedom of design: The multiple faces of subtraction in Dutch primary school textbooks. In Y. Li \& G. Lappan (Eds.), Mathematics curriculum in school education, advances in mathematics education (pp. 231-259). Dordrecht/ Heidelberg/New York/London: Springer.

Veilande, I. (2014). Contemporary study of 5th grade textbooks: Tasks on whole numbers and their compliance with mathematics Olympiad content. In K. Jones, C. Bokhove, G. Howson, \& L. Fan (Eds.), Proceedings of the International Conference on Mathematics Textbook Research and Development 2014 ICMT-2014 (pp. 477-482). Southampton: Southampton Education School, University of Southampton.

Veldhuis, M., \& van den Heuvel-Panhuizen, M. (2014). Exploring the feasibility and effectiveness of assessment techniques to improve student learning in primary mathematics education. In C. Nicol, S. Oesterle, P. Liljedahl, \& D. Allan (Eds.), Proceedings of the joint meeting of PME 38 and PME-NA 36 (Vol. 5, pp. 329-336). Vancouver: PME.

Veldhuis, M., \& van den Heuvel-Panhuizen, M. (2015). Supporting primary school teachers' assessment practice in mathematics: Effects on students' learning. https://www.ris.uu.nl/ws/ files/11827943/Veldhuis.pdf. Manuscript submitted for publication.

Vygotsky, L. S. (1980). Mind in society. Cambridge, MA: MIT Press.

Wang, T., Cai, J., \& Hwang, S. (2015). Achieving coherence in the mathematics classroom: Toward a framework for examining instructional coherence. In L. Fang, N. Y. Wong, J. Cai, \& S. Li (Eds.), How Chinese teach mathematics. Perspectives from insiders (pp. 111-148). Singapore: World Scientific.

Watson, A., \& Mason, J. (2005). Mathematics as a constructive activity: Learners generating examples. Mahwah: Lawrence Erlbaum Associates.

Watson, A., \& Mason, J. (2006a). Seeing an exercise as a single mathematical object: Using variation to structure sense-making. Mathematical Thinking and Learning, 8(2), 91-111.

Watson, A., \& Mason, J. (2006b). Variation and mathematical structure. Mathematics Teaching, 194, 3-5.

Wright, R., Martland, J., \& Stafford, A. (2000). Early numeracy: Assessment for teaching and intervention. London: Paul Chapman Publishing.

Xin, Y. P. (2007). Word problem solving tasks in textbooks and their relation to student performance. Journal of Educational Research, 100(6), 347-359.

Zazkis, R., \& Leikin, R. (2007). Generating examples: From pedagogical tool to a research tool. For the Learning of Mathematics, 27(2), 15-21. 


\section{Cited papers from Sun, X., Kaur, B., \& Novotna, J. (Eds.). (2015). Conference proceedings of the ICMI study 23: Primary mathematics study on whole numbers. Retrieved February 10, 2016, from www.umac.mo/fed/ICMI23/doc/Proceedings_ICMI_ STUDY_23_final.pdf}

Alafaleq, M., Mailizar, L., Wang, Y., \& Fan, L. (2015). How equality and inequality of whole numbers are introduced in China, Indonesia and Saudi Arabia primary mathematics textbooks (pp. 392-398).

Askew, M., (2015). Seeing through place value: An example of connectionist teaching (pp. 399-406).

Barry, A., Novotná, J., \& Sarrazy, B. (2015). Experience and didactical knowledge: The case of didactical variability in solving problems (pp. 407-414).

Bartolini Bussi, M.G. (2015). The number line: A "western" teaching aid (pp. 298-306).

Brombacher, A. (2015). National intervention research activity for early grade mathematics in Jordan (pp. 415-422).

Butterworth, B. (2015). Low numeracy: From brain to education (pp. 21-33).

Cao, Y., Li, X. \& Zuo, H. (2015). Characteristics of multiplication teaching of whole numbers in China: The application of the nine times table (pp. 423-430).

Chambris, C. (2015). Mathematical foundations for place value throughout one century of teaching in France (pp. 52-59).

Changsri, N. (2015). First grade students' mathematical ideas of addition in the context of lesson study and open approach (pp. 60-67).

Cooper, J. (2015). Combining mathematical and educational perspectives in professional development (pp. 68-75).

Ekdahl, A. L., \& Runesson, U. (2015). Teachers' responses to incorrect answers on missing number problems in South Africa (pp. 431-439).

Gervasoni, A., \& Parish, L. (2015). Insights and implications about the whole number knowledge of grade 1 to grade 4 children (pp. 440-447).

Inprasitha, M. (2015). An open approach incorporating lesson study: An innovation for teaching whole number arithmetic (pp. 315-322).

Kaur, B. (2015). The model method: A tool for representing and visualising relationships (pp. 448-455).

Lin, P.-J. (2015). Teaching the structure of standard algorithm of multiplication with 2-digit multipliers via conjecturing (pp. 456-463).

Ni, Y. (2015). How the Chinese methods produce arithmetic proficiency in children (pp. 339-345).

Pearn, C. (2015). Same year, same school, same curriculum: Different mathematics results (pp. 464-471).

Peter-Koop, A., Kollhoff, S., Gervasoni, A., \& Parish, L. (2015). Comparing the development of Australian and German children's whole number knowledge (pp. 346-353).

Sensevy, G., Quilio, S., \& Mercier, A. (2015). Arithmetic and comprehension at primary school (pp. 472-479).

Siu, M-K. (2015). Pedagogical lessons from Tongwen Suanzhi: Transmission of Bisuan (Written calculation) in China (pp. 132-139).

Wong, I. N., Jiang, C., Cheung, K.C., \& Sun, X. (2015). Primary mathematics education in Macao: Fifteen years of experiences after 1999 handover from Portugal to Mainland China (pp. 480-487).

Yang, D.-C. (2015). Performance of fourth graders in judging reasonableness of computational results for whole numbers (pp. 268-275). 
Zhang, Q-P., Cheung, K-C., \& Cheung, K-F (2015). An analysis of two-digit numbers subtraction in Hong Kong primary mathematics textbooks (pp. 488-495).

Zhao, X., van den Heuvel-Panhuizen, M., \& Veldhuis, M. (2015). Classroom assessment techniques to assess Chinese students' sense of division (pp. 496-503).

Open Access This chapter is licensed under the terms of the Creative Commons Attribution 4.0 International License (http://creativecommons.org/licenses/by/4.0/), which permits use, sharing, adaptation, distribution and reproduction in any medium or format, as long as you give appropriate credit to the original author(s) and the source, provide a link to the Creative Commons license and indicate if changes were made.

The images or other third party material in this chapter are included in the chapter's Creative Commons license, unless indicated otherwise in a credit line to the material. If material is not included in the chapter's Creative Commons license and your intended use is not permitted by statutory regulation or exceeds the permitted use, you will need to obtain permission directly from the copyright holder. 